\title{
Thermodynamic Aspect and Diffusion Model on Interdiffusion of Laminate Structure
}

\section{Shing-Hoa Wang}

Associate Professor, Department of Mechanical and Marine Engineering, National Taiwan Ocean University, Keelung, Taiwan, R.O.C.

\section{Recommended Citation}

Wang, Shing-Hoa (2000) "Thermodynamic Aspect and Diffusion Model on Interdiffusion of Laminate Structure," Journal of Marine Science and Technology. Vol. 8: Iss. 2, Article 6.

DOI: $10.51400 / 2709-6998.2460$

Available at: https://jmstt.ntou.edu.tw/journal/vol8/iss2/6

This Research Article is brought to you for free and open access by Journal of Marine Science and Technology. It has been accepted for inclusion in Journal of Marine Science and Technology by an authorized editor of Journal of Marine Science and Technology. 


\section{Thermodynamic Aspect and Diffusion Model on Interdiffusion of Laminate Structure}

\section{Acknowledgements}

The author acknowledges and deeply appreciates professors D. L. Olson, David. K. Matlock, and Chet. VanTyne in Metallurgical and Materials Engineering Department of Colorado School of Mines, Golden, Colorado, USA, for intensively discussing the thermodynamic approach of excess vacancy gradient and reviewing the diffusion model analysis respectively. 


\title{
THERMODYNAMIC ASPECT AND DIFFUSION MODEL ON INTERDIFFUSION OF LAMINATE STRUCTURE
}

\author{
Shing-Hoa Wang
}

Keywords: Interdiflusion, Kirkendall Void, Thermodynamic, Strain Enhanced Diffusion.

\begin{abstract}
A non-uniform system such as microsegregation, heterogeneous microstructure and multiple-layer deposition of thin films, always exists in the engincering materials and the electronic materials for solid state devices. As a consequence of interdiffusion under high temperature exposure, The dynamical changes of compsition profiles and vacancies could lead to miaterials in earlier failure and reduce the life time of the component. Several theorctical fundamentals have been proposed on different aspects, including(1) the void formation at the steepest concentration gradient:(2) thermodynamic view points of excess vacancy flux;(3) the model of interdiffusion for dynamic composition profile change; and(4) stress gradient induced strain enhanced diffusion, to systematically analyze the interdiffusion between layers in a laminale structure.
\end{abstract}

\section{INTRODUCTION}

Generally in structural materials or electronic materials for solid state devices, non-uniform compositions always occur during material processing and fabrication, for example, in casting, welding, sintering, thin film deposition, composite manufacture, production of multiple layer electronic devices, coating, etc. Previous studies have shown that materials with nonuniform composition exhibit low temperature mechanical properties $[1,2]$, high temperature mechanical properties [3], physical properties[4] and chemical properties $[5,6]$ that are significantly different from those of wrought materials with uniform composition.

The defects related to the concentration gradient resulting from compositional fluctuation due to materials processing have bcen studicd recently. Several cases have been investigated: 1) Berry et. al. [5] ob-

Paper Received September 22, 2000, Revised November 15, 2000, Accepted November 20, 2000. Author for Correspondence: S. H. Wang.

*Associate Professor, Department of Mechanical and Marine Engineering, National Taiwan Ocean University, Keelung, Taiwan, R.O.C. served the stress corrosion crack path at cast fully austenitic stainless stccl preferentially propagates through the steepest concentration gradient region, instead of the anodic-dissolution region of least corrosion resistance. Because the lower local surface energy is cxisted at the steepest concentration gradient. 2) Faligue cracking in high copper content of cast coppernickel single crystal is shown by Wahid [2] that the crack path follows the steepest concentration gradient region. 3) Holt et. al. [7] proposed with both a temperature and a concentration gradicnt present along the dendrite/liquid interface, the fluid will be forced out of the mushy zone and resulted in an hot cracking tendency by the interfacial tension driven fluid flow.

At high temperatures, materials with local composition gradients experience interdiffusion between the different composition regions. Interdiffusion results in a more homogeneous material but can also lead to Kirkendall pore formation $[8,9]$ and enhanced dislocation motion. Several studies $[8,9,10]$ have shown that high temperature failures associated with non-uniform composition can be attributed to Kirkendall void formation.

For example, roll bonded alternate two component laminate composite of nickel with $\mathrm{Cu}-\mathrm{Ni}$ solid solutions containing $8.9,18.9,28.6,37.3$, and 48.3 at. $\% \mathrm{Cu}$ were fabricated, as shown in figure 1,10 simulate physically the microsegregation occurring in solidified Monel 400 weld metal $[9,11,12]$. The results show that the crecp behavior is strongly influenced by the degree of interdiffusion and amplitude of the compositional fluctuation, as a result of the driving force of the simulated microsegregation. The apparent activation energy $Q$ is dependent on the applied stress. As stresses increase, the deformation mechanisms suggested vary from short circuit diffusion, to thermal lattice selfdiffusion, to high atomic mobility selfdiffusion which is attributed to the athermal excess vacancies. Changes in stress exponent $\mathrm{n}, \mathrm{Q}$, and the structure dependent constant $\mathrm{A}$ with time are correlated with the dynamic interdiffusion due to the homogenization process $[11,12]$. Thus, it is necessary to thoroughly understand the fundamental of interdiffu- 
sion as well as its effect in order to optimize material properties.

Based on the previous experimental results and data $[9,10]$, this paper will extend the concepts of (i) local surface energy variation with the position dependence of concentration gradient [10], (ii)thermodynamic view of excess vacancy flux, (iii)diffusion model for composition profile prediction and (iv)strain enhanced interdiffusion in a non-uniform system, to the defect of void formation during high temperature exposure. The results of this study provide a fundamental basis for modeling the dynamic nature of composition gradients induced by processing.

\section{KIRKENDALL VOID FORMATION AT THE STEEPEST CONCENTRATION GRADIENT [10]}

At high temperature environment, the critical radius (r) of a void which forms by vacancy condensation due to interdiffusion between solute rich and lean regions in a non homogeneous system can be rewritten the GibbsThompson equation by incorporating a composition

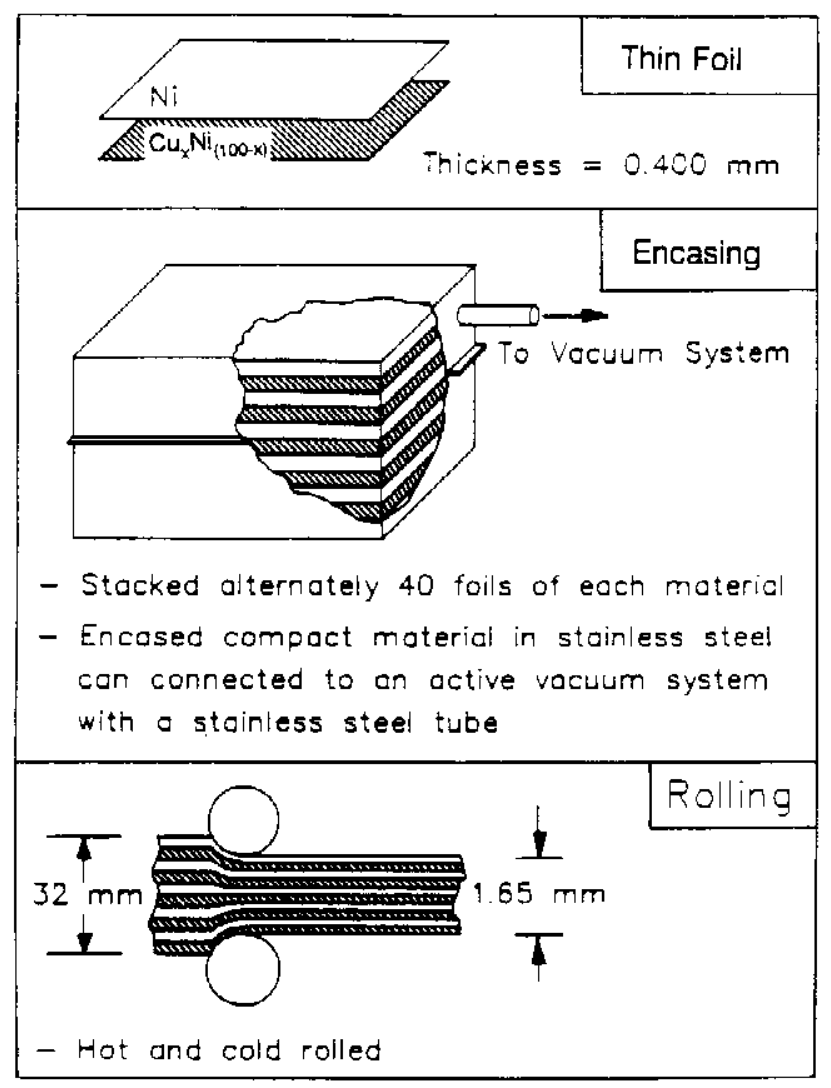

Fig. I. Schematic summary of manufacturing procedures to produce nickelcopper laminate composites. gradient [10]:

$$
\begin{aligned}
& \ln \frac{N_{1}}{N_{10}}=\frac{2 \gamma_{h o r}(c)}{k T A_{0} r} \\
& \gamma_{h e^{\prime}}(c)=\gamma_{h o m}(c)-\gamma_{i}(c) \\
& \gamma_{i}(c)=2 B \int G\left(\frac{d c}{d x}\right)^{2} d x
\end{aligned}
$$

where:

$\gamma_{h o m}(\mathrm{C})$ is the concentration dependent surface free energy for a homogeneous alloy, $\gamma_{i}(\mathrm{C})$ is the local specific interfacial free energy due to a concentration gradient, $\gamma_{h e r}(c)$ is the concentration dependent surface free energy for a heterogeneous alloy, $A_{0}$ is Avogadro's number, $B$ is the number of moles per unit volume, $G$ is an energy coefficient which can be calculated from a solid solution thermodynamic and activity data, and dc/ $\mathrm{dx}$ is composition gradient. The $\gamma_{i}(\mathrm{C})$ term is the CahnIlilliard [13] expression which corrects the reference energy state for a non-uniform condition. Equation (2) suggests that the local specific surface free energy is concentration gradient dependent. The steeper the concentration gradient the lower the localized specific surface free energy. The position where has the lowest specific surface energy is the favorite site for void formation. Because the place where has lower specific surface free energy results in a lower free energy for void nucleation and growth thermodynamically.

From surface energy considered the concentration gradient mentioned above, a detailed quantitative analysis of composition profile by Wang et. al. [10] has shown that the location at about 40 at. Pct. where is the steepest concentration has the lowest surface energy in a pure copper and pure nickel diffusion couple. The location with the minimum surface energy expects to be the favorite site for void formation. The roll bonded laminate composites with alternating $21 \mu \mathrm{m}, 41 \mu \mathrm{m}$ or $48 \mu \mathrm{m}$ layers of purc nickcl and a nickel-37.3 at. pet. copper solid solution alloy after annealing and after creep were used to experimental verification of the void location. Voids were observed in the'samples and the location of the voids are indicated by the vertical line superimposed on the composition profile of Figs 2. and 3.

Figure 2 illustrates the condition for annealing. The voids are located at the steepest concentration gradient. Both the interdiffusion composition profile and the void position are independent of the composite layer thickness. In contrast, for creep case shown in Figure 3 , the layer thickness in $48 \mu \mathrm{m}$ of laminate composite extended a wider diffusion distance than the thin layer of $21 \mu \mathrm{m}$ materials does because the stress gradient induced strain enhance diffusion across the interface is extensive in the thick $48 \mu \mathrm{m}$ matcrials[9]. The measure- 

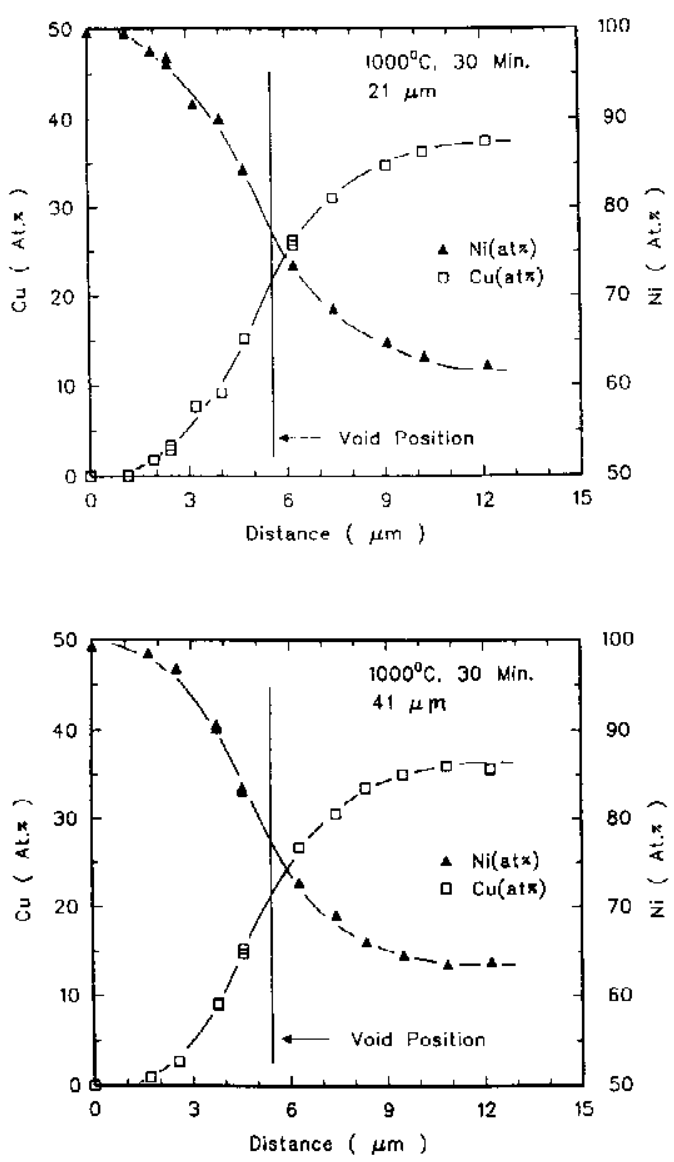

Fig. 2. Voids position superimposed on composition profiles on samples of the (a) $21 \mu \mathrm{m}$ layer thickness (b) $41 \mu \mathrm{m}$ layers thickness, material after annealing for 30 minutes at $1000^{\circ} \mathrm{C}$.

ment indicates that the void position still follows the steepest concentration gradient even for the thick laminate composite with extensive interdiffusion. From the above proposed and measured results, the conclusion is that the void location correlates with the steepest gradient in the composition profile. Voids were predicted and verified to develop at a location with a minimum interfacial energy attributed to the steepest concentration gradient, based on Cahn-Hillard [13] analysis in a non-uniform system.

\section{THERMODYNAMIC VEIEWPOINT IN EXCESS VACANCY FLUX GRADIENT}

Pore formation due to the presence of excess vacancies in a diffusion couple was observed [10] in the laminate structure of $\mathrm{Ni}$ with about $37.3 \mathrm{at} \% \mathrm{Cu}$ alloy shown in Fig. 4. The excess vacancies calculation follows the diffusion analysis approach addressed by Wang et. al.[10]. However, the effect of concentration

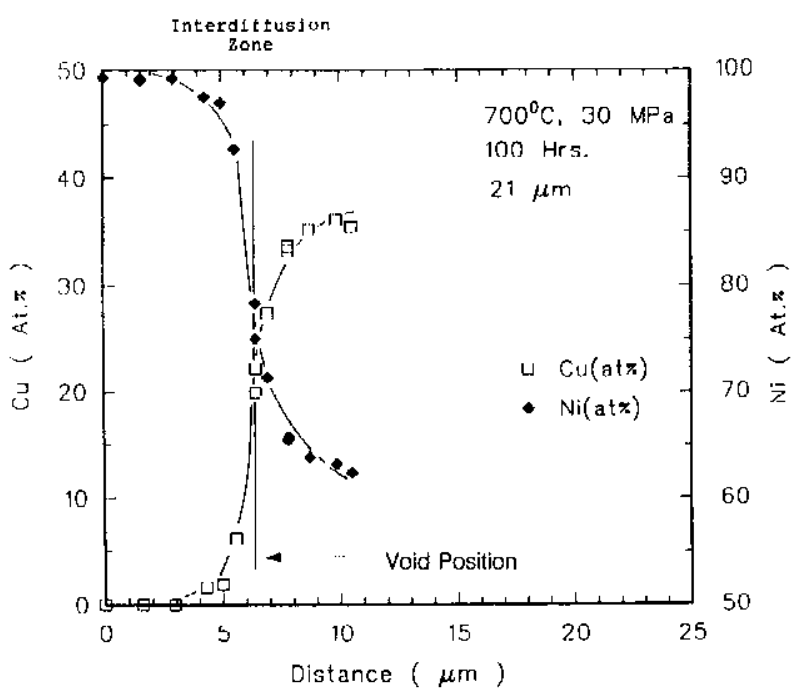

( a )

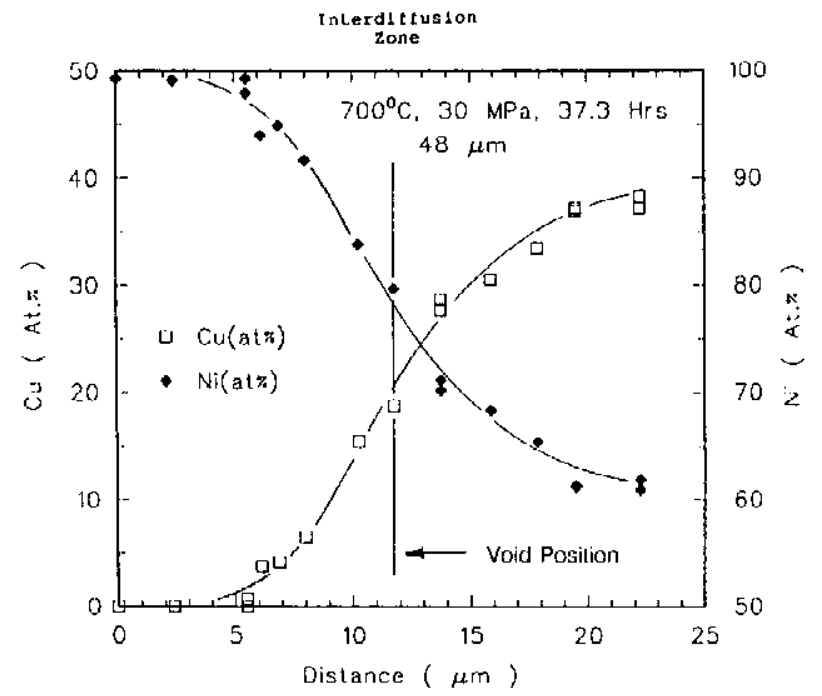

(b)

Fig. 3. Vuids pusition superimposed on composition profiles on samples of the (a) $21 \mu \mathrm{m}$ layer thickness (b) $48 \mu \mathrm{m}$ layer thickness, material after creep at $7(X)^{\circ} \mathrm{C}$ and $30 \mathrm{MPa}$. 191

gradient on excess vacancy can also be viewed from another thermodynamic aspect. In this paragraph an analysis based on chemical potential is presented for the vacancy concentration gradient which develops as a result of interdiffusion. The presence of excess vacancies will induce an extra driving force for diffusion. This excess vacancy chemical potential could stimulate 

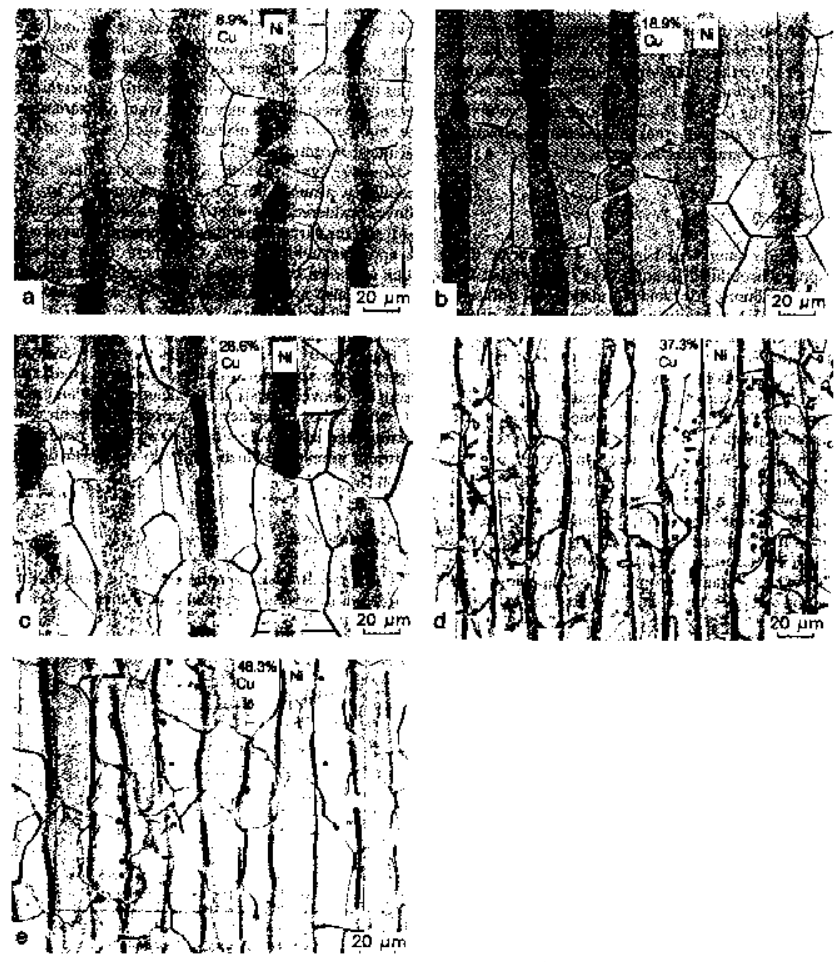

Fig. 4. Light micrographs of annealed larninate composites of pure $\mathrm{Ni}$ to $\mathrm{Ni}-\mathrm{Cu}$ solid-solution alloys with copper content in at \% of (a) $8.9 \%$; (b) $18.9 \%$; (c) $28.6 \%$; (d) $37.3 \%$; and(e) $48.3 \%$. Samples were anncaled for $30 \mathrm{~min}$ at $1000^{\circ} \mathrm{C}$ : nitric-acetic etchant. [10]

cross terms such as vacancy-copper, vacancy-nickel, and nickel-copper interactions, which would play an important role in defining the net total flux at equilibrium. In order to investigate the excess vacancy concentration induced by the unequal diffusion rates and flux gradicnts, evaluation of both nickel and copper gradients is required. At equilibrium, the excess vacancies flux $\left(J_{V a c}\right)$, required to balance the copper flux $\left(J_{C u}\right)$ and the nickel flux $\left(I_{N i}\right)$, is written as

$$
J_{C u}+J_{N i}+J_{V a c}=0
$$

The thermodynamic phenomenological equations for a 3-component system in one dimension can be given by

$$
\begin{aligned}
& J_{C u}=-M_{C u C u} \frac{d \mu_{C u}}{d x}-M_{C u N i} \frac{d \mu_{N i}}{d x}-M_{C u V a r i} \frac{d \mu_{V a c}}{d x} \\
& J_{N i}=-M_{N i C u} \frac{d \mu_{C u}}{d x}-M_{N i N i} \frac{d \mu_{N i}}{d x}-M_{N i V a c} \frac{d \mu_{V a c}}{d x} \\
& J_{V a c}=-M_{V a c C u} \frac{d \mu_{C u}}{d x}-M_{V a c N i} \frac{d \mu_{N i}}{d x}-M_{V a c V a c} \frac{d \mu_{V a c}}{d x}
\end{aligned}
$$

where $M_{i j}$ is atomic mobility terms between copper, nickel and vacancy, as well as between species itself of copper-copper, nickel-nickel and vacancy-vacancy. $\mu_{i}$ is chemical potential, and $N_{i}$ is the mole fraction of each species. From Gibbs-Duhem equation

$$
N_{C u} d \mu_{C u}+N_{N i} d \mu_{N i}+N_{V a c} d \mu_{V a c}=0
$$

Thus

$$
N_{C u} \frac{d \mu_{C u}}{d x}+N_{N i} \frac{d \mu_{N i}}{d x}+N_{V a c} \frac{d \mu_{V a c}}{d x}=0
$$

chemical potential gradients of copper and nickel respectively are

$$
\begin{aligned}
\frac{d \mu_{V a c}}{d x} & =-\frac{N_{C u} \frac{d \mu_{C u}}{d x}+N_{N i} \frac{d \mu_{N i}}{d x}}{N_{V a c}} \\
d \mu_{C u} & =-\frac{k T}{N_{C u}} \frac{d N_{C u}}{d x}\left(1+\frac{\partial \ln \gamma_{C u}}{\partial \ln N_{C u}}\right) \\
\frac{d \mu_{N i}}{d x} & =-\frac{k T}{N_{N i}} \frac{d N_{N i}}{d x}\left(1+\frac{\partial \ln \gamma_{N i}}{\partial \ln N_{N i}}\right)
\end{aligned}
$$

By combining equations from 4 to 12 with an assumption that the coefficients $M_{i j}=M_{j i}$ satisfy the Onsager reciprocal relation [14], the derivation of excess vacancy flux can be expressed as

$$
I_{V a c}=-k T\left\{(A+B) \frac{d N_{C u}}{d x} \eta_{C u}+(A+C) \frac{d N_{N i}}{d x} \eta_{N i}\right)
$$

Where

$$
\begin{aligned}
& A=\frac{M_{N i N i}-2 M_{C u N i}+M_{C u C u}}{N_{V a c}} \\
& B=\frac{M_{N i C u}-M_{C u C i u}}{N_{C u}} \\
& C=\frac{M_{N i N i}-M_{C u N i}}{N_{N i}} \\
& \eta_{C u}=1+\frac{\partial \ln \gamma_{C u}}{\partial \ln N_{C u}} \\
& \eta_{N i}=1+\frac{\partial \ln \gamma_{N i}}{\partial \ln N_{N i}}
\end{aligned}
$$

$\mathrm{K}$ is Boltzman constant, $\gamma$ is an activity coefficient, and $\mathrm{T}$ is temperature. Equation (13) shows that the total excess vacancy flux is a function of the cross terms, the concentration gradients and the thermodynamic factor $\eta$. The appropriate expression for thermodynamic coefficients $M_{i j}$ still needs to be determined even though solutions have been proposed by Manning [15] based on the assumption of $\mu_{\text {vacancy }}=0$. This analysis shows that the vacancy flux depends on the concentration gradients of nickel and copper. It can be coupled with the mea- 
sured [9] or predicted composition profile to predict the position dependence of excess vacancy flux and divergence flux, as well as, the location where has the highest vacancy concentration. The location where the excess vacancy concentration is highest will correspond to the location of the void formation and the highest dislocation climb rate. Thus, samples with a high excess vacancy concentration should result in higher averagc creep rates and earlier failures.

\section{INTERDIFFUSION MODEL}

It is expected that the slope and amplitude of the concen-tration profilles decrease during creep as shown schematically in Fig. 5a, since the driving force of concentration gradient for mass transport dynamically diminishes. To illustrate the effects of creep exposure on the composition gradients across the laminate composites, Figure $5 \mathrm{~b}$ presents composition profiles
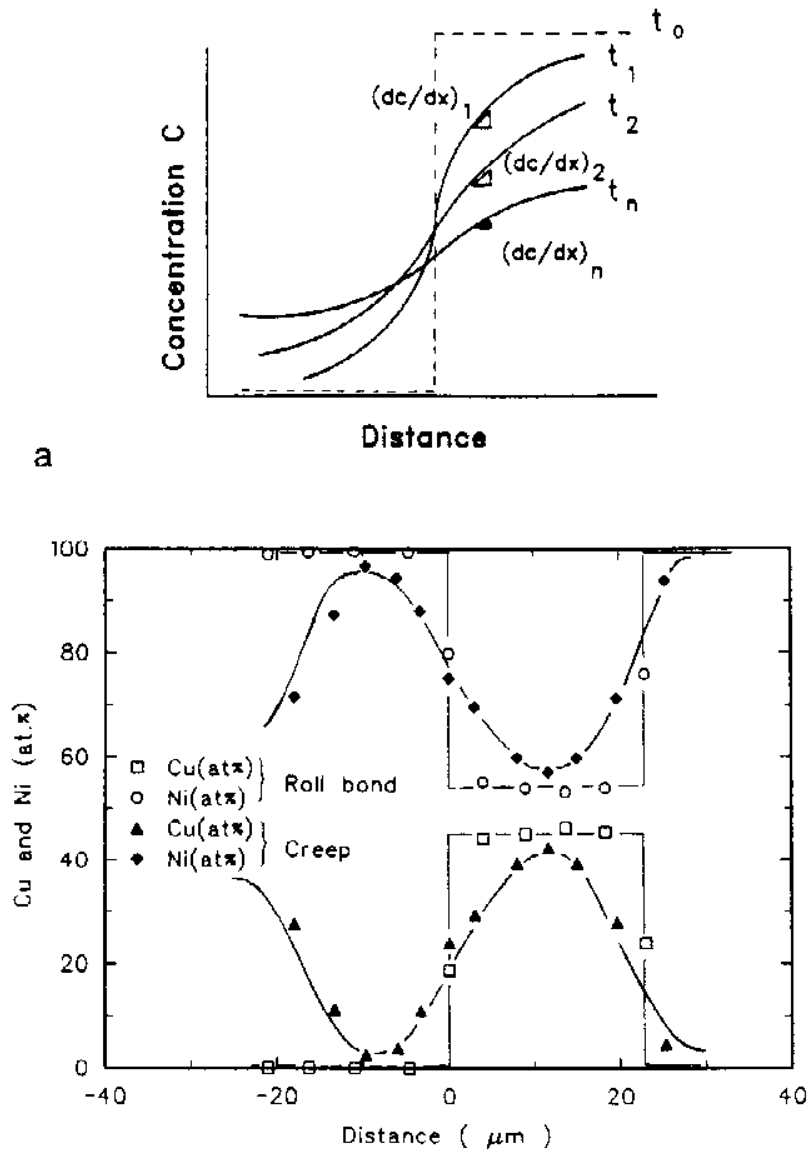

b

Fig. 5. The change in the composition profile within one composition profile period (a) schematical illustration (b)after creep for 100 hours at $700^{\circ} \mathrm{C}$ and $30 \mathrm{MPa}$ measured both before and after creep. The initial composition illustrates the square-wave form of the composition profile present after hot and cold rolling, After creep for 100 hours at $700^{\circ} \mathrm{C}$ and $30 \mathrm{MPa}$ the composition profille is observed to have significantly changed due to the effects of interdiffusion and the resulting profile approximates a sine-wave function. In order to describe the obscrved changes in the composition gradients during high temperature, a proper diffusion model needs to be developed. In the following paragraphs a model based on (1) short time diffusion, (2) impingement, (3) and homogenization is presented. This predicted composition profile can be utilized to estimate the aforementioned thermal excess vacancies concentration due to interdiffusion. A typical result of the excess vacancies calculation follows the diffusion analysis approach has been reported [10]. The primary assumptions for this interdiffusion model are:

1. Effects of applied stress and stress gradient are negligible.

2. No athermal excess vacancies are generated from forced dragging of dislocation jogs.

3. Effect of electron migration is negligible.

Interdiffusion can be evaluated in a three stage process illustrated schematically in Fig. 6. Figure 6 indicates the initial step function associated with the asfabricated composite (Fig. 6a) and three stages in the diffusion process: (i) stage 1 (Fig. 6b), in which the interfacial diffusion profiles are equivalent to those observed in a semi-infinite diffusion couple (i.e. there is no interactions between layers); (ii) stage 2 (Fig. 6c), the condition at which impingement occurs between the profiles; and (iii) stage 3 (Гig. 6d) a condition referred to as homogenization in which the profile amplitude decreases with time.

\section{Stage I: short time diffusion}

The short time diffusion (Fig. 6b) solution assumes that each component can be treated as a finite plane source in which the composition at the centerline of each layer is unchanged and equal to the initial composition. Note, $x=0$ corresponds to the center of the nickel layer. The complete modified Gaussian error function solution of the concentration profile, $C(x, t)$, for nickel is

$$
C_{N i}(x, t)=\left(\begin{array}{c}
C_{N i}^{0} \\
2
\end{array}\right)\left\{\operatorname{erf}\left[\begin{array}{c}
(h-x) \\
2 \sqrt{\tilde{D}} \sqrt{t}
\end{array}\right]+\operatorname{erf}\left[\begin{array}{c}
(h+x) \\
2 \sqrt{\tilde{D}} \sqrt{t}
\end{array}\right]\right\}
$$

\section{Here}




$$
C_{N i}^{0}=C_{N i}^{0}(\text { pure nickel })+C_{N i}^{0}\left(C u_{X} N i_{(100-x)} \text { alloy }\right)
$$

Similarly, the solution of the concentration profile for copper is written as

$$
C_{c u}(x, t)=\left(\frac{C_{c u}^{0}}{2}\right)\left\{\operatorname{erf}\left\lfloor\frac{(h-x)}{2 \sqrt{\tilde{D}} \sqrt{t}}\right\rfloor+\operatorname{erf}\left\lfloor\frac{(h-x)}{2 \sqrt{\tilde{D}} \sqrt{t}}\right\rfloor\right\}
$$

Here, $x=0$ corresponds to the center of the copper layer and

$$
C_{c u}^{0}=C_{c u}^{0}\left(C u_{x} N i_{(100-x)} \text { alloy }\right)
$$

where $\tilde{D}$ is the composition dependent chemical diffusivity, $\mathrm{t}$ is the time, $C_{N i}{ }^{0}$ and $C_{C u}{ }^{0}$ are the initial

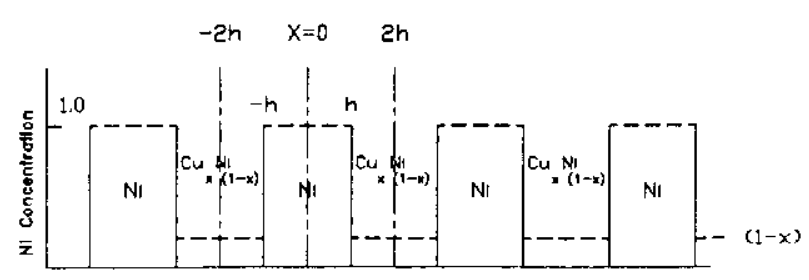

(o) At IImo Zoro
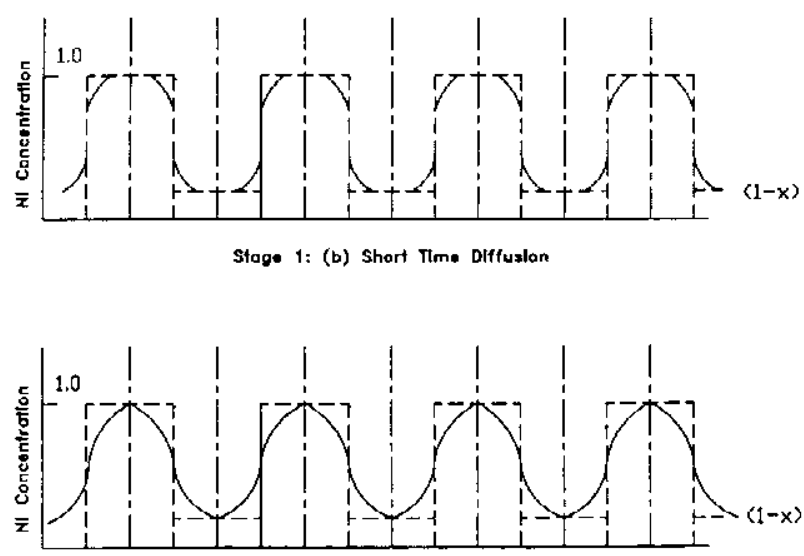

Stoge 2: (c) Impingament

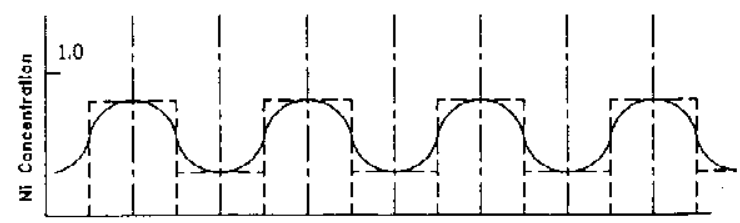

Sloge 3: (d) Homogenizotion

Fig. 6. Illustration of periodic composition profile evolution from initial step function to a smooth sinusoidal function through three proposed stages. concentrations of nickel or copper in the finite plane sources, and $2 h$ is the initial layer thickness.

\section{Stage II: impingement}

Impingement corresponds to the condition where the interdiffusion profile mects at the mid point of a layer as shown in Fig. 6c. $\Lambda$ t this point the layer centerline concentration begins to decay and the solution for stage I no longer applies. The condition for impingement is described by a specific time referred to as the impingement time, $t_{i m p}$. $t_{i m p}$ can be found from Equation (19) with $x= \pm 2 h$ and a specified value for the nickel composition at the mid point. It is given by

$$
t_{i m p}=\frac{1}{\left[\frac{2 \sqrt{D}}{3 h} \operatorname{erf}^{-1}\left\{\frac{C_{N i}\left( \pm 2 h, t_{i m p}\right)}{C_{N i}^{0}}\right\}\right]^{2}}
$$

similarly for copper layer, $t_{\text {imp }}$ is expressed by

$$
t_{i m p}=\frac{1}{\left[\frac{2 \sqrt{\tilde{D}}}{3 h} \operatorname{erf}^{-1}\left\{\frac{C_{c u}\left( \pm 2 h, t_{i m p}\right)}{C_{c u}^{0}}\right\}\right]^{2}}
$$

Note for diffusion times greater than $t_{i m p}$ the composition profile can be approximated by a periodic wave function. This function is referred to a long range solution in stage III.

\section{Stage III: homogenization}

After impingement the amplitude of the sinusoidal profile gradually decreases and the curvature of the composition profiles smoothes to approximate more closely a sinusoidal function as shown in Fig. 6d. In general homogenization, the trigonometrical series type of solution converges satisfactorily for moderate and large times. The solution is therefore

$$
C_{N i}(x, t)=\sum_{n=1}^{\infty} A_{n} \sin \frac{n \pi x}{2 h} \exp \left[-\tilde{D}\left(\frac{n \pi}{2 h}\right)^{2}\left(t-t_{i m p}\right)\right]
$$

where

$$
A_{n}=\frac{1}{h} \int_{0}^{2 h} g(x) \sin \frac{n \pi x}{2 h}
$$

with the initial boundary condition (i.e. $t=0$ corresponds to $t=t_{i m p}$ as defined in stage II) 


$$
C( \pm 2 h, 0)=g( \pm 2 h)=C_{N i}^{0}\left(C u_{s} N i_{(100-x)} \text { alloy }\right)
$$

$g(x)$ is an initial concentration function just before homogenization. Similar principles can be applied to describe homogenization of the copper concentration profile.

$$
C_{c u}(x, t)=\sum_{n=1}^{\infty} A_{n} \sin \frac{n \pi x}{2 h} \exp \left[-\widetilde{D}\left(\frac{n \pi}{2 h}\right)^{2}\left(t-t_{i m p}\right)\right]
$$

Besides using the solutions to predict the composition profile, the position dependence of vacancy flux, flux divergence, and concentration of excess vacancies [10] can be cstimated from the results of predicted profile. The dynamic composition gradients during high temperature application can be described by a model based on (1) short time diffusion (2) impingement (3) and homogenization. For high temperature applications, both the micro-segregation amplitude and wavelength in solidified microstructures must be controlled to optimize properties.

\section{STRESS GRADIENT INDUCED STRAIN ENHANCED DIFFUSION}

Under applied stress, the strain enhanced diffusion generated from greater stress gradients at the interface has been observed on $48 \mu \mathrm{m}$ materials [9]. Therefore, in a specific case predictions of the composition profile need to account for the effect of deformation (i.e. strain enhance diffusion). In this section a model which incorporates stress in composition profile prediction is presented. The primary assumptions for this interdiffusion model are:

1. Effects of strain enhanced diffusion must be considered.

2. Initiation of tertiary creep is based on the void growth mechanisms.

3. No athermal excess vacancies are generated from forced dragging dislocation jogs.

This diffusion model is limited to composites with interlayer thicknesses of about $40 \mu \mathrm{m}$ under test conditions of high temperature and low applied stress Fig. 3. Basically, interdiffusion during creep can be evaluated in a three stage process illustrated schematically in Fig. 6. An additional criteria needs to be considered in order to stop the interdiffusion process. This criterion is referred here as "time, strain and strain rate for tertiary initiation", that is "point at which power law starts breakdown".

\section{Stage I: short time diffusion}

The solution of the concentration profile, $C(x, t, \varepsilon)$ at a given strain rate can be predicted based on the Fara and Balluffi [16] derivation and the formulation is given as

$$
\begin{aligned}
C(x, t, \varepsilon)= & Q\left\{\frac{2 \varepsilon}{\pi \tilde{D}[1-\operatorname{cxp}(-2 \varepsilon t)]}\right\}^{\frac{1}{2}} \\
& \exp \left\{\frac{-\varepsilon x^{2}}{2 \tilde{D}[\exp (2 \xi t)-1]}\right\}
\end{aligned}
$$

Where $\varepsilon$ is the strain rate, $Q$ is the amount of solute. The features of this solution are that : (1) the solution is not an error function; and (2) diffusion is linear time, $t$, dependent instead of conventional square root of time (i.c. $\sqrt{ } t$ ). However compositional interdiffuison and void growth from excess vacancies are competing. The specific time at which the tertiary initiation, caused by void growth to a critical radius, is referred to as $t$ tertiary. If time $\mathrm{t}$ for interdiffusion at $C$ $(x, t, \varepsilon)<t_{\text {tertiary }}$, diffusion will proceed until stage II (Fig. 6c) where impingement occurs between the profiles. If void nucleation occurs prior to impingement, then the predicted composition profile is completely described by Equation (29) for $t=t_{\text {tertiary. }}$.

\section{Stage II: impingement}

The time of impingement is described by $t_{i m p}$. $t_{i m p}$ can be calculated implicitly from Equation (29) with $x$ $=2 h$ and the copper composition at the mid point. It is given as

$$
\begin{aligned}
\frac{C\left( \pm 2 h, t_{i m p}, \varepsilon\right)}{Q}= & \left\{\frac{2 \varepsilon}{\pi \tilde{D}\left[1-\exp \left(-2 \varepsilon t_{i m p}\right) \mid\right.}\right\}^{\frac{1}{2}} \\
& \exp \left\{\frac{-2 \varepsilon h^{2}}{\tilde{D}\left[\exp \left(2 \varepsilon t_{i m p}\right)-1\right]}\right\}
\end{aligned}
$$

If

$t_{\text {imp }}$ at $C(x, t, \varepsilon)<t_{\text {tertiary }}$ 
The diffusion process continues to stage III, i.c. homogenization. If void nucleation occurs at $t_{i m p}$, then $t_{\text {imp }}=t_{\text {tertiary. }}$.

\section{Stage III: homogenization}

After impingement, the curvature of composition profiles become smooth and the driving force of the stress gradient to promote strain enhanced diffusion diminishes. In addition, the vacancy concentration will tend to a constant with a balance between the effects of source and sinks due to thermal recovery processes. Strain enhanced diffusion, Equation (29) may not be valid any more. Thus, the trigonometrical series type diffusion solution in equation (25), (28) applies, and the maximum time for chemical diffusion is when $t=t_{\text {tertiury }}$ $-t_{\text {imp. }}$. The formulation can be written as

$$
C(x, t)=\sum_{n=1}^{\infty} A_{n} \sin \frac{n \pi x}{2 h} \exp \left\lceil-\tilde{D}\left(\frac{n \pi}{2 h}\right)^{2}\left(t-t_{i m p}\right)\right\rceil
$$

Note Kirkendall void formation and growth is enhanced by short circuit diffusion path including surfaces, grain boundaries, and dislocation cores. In addition, based on experimental observation $[9,10]$ (Fig. 3), it is apparent that with an increase layer thickness, the possibility that $t=t_{\text {tertiary }}$ is achieved prior to $t=t_{\text {imp }}$ increases. For this case stage II and III in the diffusion profiles are not observed. The physical simulation of microsegregation amplitude effects $[11,12]$ and wavelength effects [9] provide a fundamental and characteristic understanding of the importance of dynamic concentration gradients on high temperature properties. Therefore at high temperatures, both the microsegregation amplitude and wavelength must be considered in order to optimize the properties in laminate structure and solidified microstructures.

From this presentation of the effects of microsegregation amplitude (i.e. the composition amplitude) on high temperature chemical and mechanical behavior in conjunction with the conclusion of microsegregation wave length effect [9] (i.e. the thickness of layer) in previous publication, a material of laminate structure with good high tempcrature application needs to possess an optimum amplitude of microsegregation (composition) and a small wave length of microsegregation (thin thickness of deposition layer), as it is possible by controlling material processings. For example, in welding process, small wave length and amplitude of microsegregation can be obtained simultaneously by means of fast cooling rate during joining and post-weld heat treatment after. In multiple layers of thin film deposition process, thin thickness and small amplitude of composition between layers can be obtained by means of controlling deposition current, voltage and time.

\section{CONCILUSIONS}

1. The compositional fluctuation will affect the materials performance, because all the nucleation and growth of defects, such as crack and void, predominate by the local surface free energy which is associated with the position dependence of concentration gradient. The excess local solute quantity resulting from the location where is steepest concentration gradient should minimize the local specific surface free energy and reduce the resistance for defect either formation or propagation.

2. Thermodynamic analysis shows that the position dependence of vacancy flux depends on the concentration gradicnts (profiles). It can be coupled with the predicted composition profile to estimate the position dependence of excess vacancy flux, divergence flux, and the location where has the highest vacancy concentration.

3. To help explain the chemical and mechanical heterogeneity of the laminate structure, some basic concepts of thermodynamic and interdiffusion are briefly presented here. These concepts include Kirkendall void formation at the steepest concentration gradient, thermodynamic view in excess vacancy flux gradient, a 3-stage diffusion model, and stress gradient induced strain enhanced diffusion.

4. The predicted dynamic composition profiles (gradients) on either interdiffusion or stress gradient induced strain enhanced diffusion during high tcmperature application can be described by a 3-stage diffusion model based on (1)short time diffusion (2) impingement and (3)homogenization.

\section{ACKNOWI.FDGEMENTS}

The author acknowledges and deeply appreciates professors D. L. Olson, David. K. Matlock, and Chet. VanTyne in Metallurgical and Materials Engineering Department of Colorado School of Mines, Golden, Colorado, USA, for intensively discussing the thermodynamic approach of excess vacancy gradient and reviewing the diffusion model analysis respectively.

\section{REFERENCES}

1. A. Wahid, D.L. Olson, D.K. Matlock, and T.J. Kelly: "Role of Composition Gradients in Environmentally Promoted Wcld Cracking", in Proc. 1st Int. Conf. on 
Heat-Resistant Materials, Fontana, Wisconsin, USA, ed. by K. Natesan, pp. 447-452; Materials Park, OH, ASM International (1991).

2. A Wahid: PhD thesis, Colorado School of Mines, Golden, CO, USA, (1992).

3. S.H. Wang: J. of Marine Science and Technogy, Vol. 2, No. 1, pp. 17-24 (1994).

4. S.K. Saha and D.C. Agrawal: J. Am. Ceram. Soc., 71, 1424 (1992).

5. G.L. Berry, D.L. Olson, and D.K. Matlock: Mater. Sci. Eng., A 148, 1-6 (1991).

6. W.A. Baeslack III, J.C. Lippold, and W.F. Savage: Weld. J., 58, (6), 168s (1979).

7. M.Holt, D,L.olson, and C.E.Cross: Scr. Met. et Mater., Vol. 26, pp. 1119-1124 (1992).

8. I.D. Choi, D.K. Matlock, and D.L. Olson: Mater. Sci. Eng., A 124, L.15-I.18 (1990).

9. S.H. Wang, D.K. Matlock, and D.L. Olson: Scr. Met. et Maler., 27, P. 35 (1992).

10. S.H. Wang, D.K. Matlock, and D.L. Olson: Mater. Sci. Eng., A167, pp. 139-145 (1993).

11. S.H. Wang, D.K. Matlock, and D.L. Olson: "physical Simulation for the Creep Behavior of Solidified Metal", in International Trends in Welding Science and Technology, Proc. 3rd Int. Conf. On Trends in Wclding Research, Gatlinburg, Tennessee, US $\Lambda$, ed. by S.A. David and J.M. Vitek, pp. 605-609; Materials Park, OH, ASM International (1992).

12. S.H. Wang, D.K. Matlock, and D.L. Olson: Science and Technology of Welding and Joining, Vol. 4, No. 3, pp.
170-177 (1999).

13. J.W.Cahn, and J.E. Hilliard: J. Chem. phys, Vol. 28, No. 2, pp. 258-267 (1958).

14. J.R. Manning: Diffusion Knctics for Atoms in Crystals, D. Van. Nostrand Co., Inc., Princeton, N.J., (1968).

15. J.R. Manning: Met. Trans., Vol.1A, P. 499 (1970).

16. H. Fara, R.W. Balluffi: J. Appl. Phys., Vol. 29, No. 7, p. 1133 (1958).

\section{交替鱟層結構相互擴散之熱力學觀 及擴散模式}

$$
\text { 王星 豪 }
$$

國立台灣海洋大學機械與輸機工程學系

$$
\text { 摘 要 }
$$

工程材料及電子材料有中，一直都無法避免非 均質系统的事嘪存在现象, 然而在工程應用中常图受 到温度影㗽, 産生相互擴散, 而導致Kirkendall㜾洞 形成及破製現象發生, 本研究认週期式 2 元交替番状 結構模擬凝固化偏析微結構或電一多層鍍膜結構, 繼 以等力燓䘽點、擴散模式, 以及應力梯度誘發應變強 化擴散模式, 討論相互摭散導致動態成份濃度梯度分 佈變化, 造成過量原子孔洞通量與Kirkendall void形 成之關連性。 